\title{
Correction to: One-dimensional drift-flux correlations for two-phase flow in medium-size channels
}

\author{
Takashi Hibiki ( $ه)$
}

School of Nuclear Engineering, Purdue University, 400 Central Drive, West Lafayette, IN 47907-2017, USA

(c) The Author(s) 2020, Corrected Publication November 2020

Correction to:

Takashi Hibiki

One-dimensional drift-flux correlations for two-phase flow in medium-size channels

Experimental and Computational Multiphase Flow 2019, 1(2): 85-100

https://doi.org/10.1007/s42757-019-0009-y

The article "One-dimensional drift-flux correlations for two-phase flow in medium-size channels" written by Takashi Hibiki, was originally published electronically on the publisher's internet portal (currently SpringerLink) on 17 April 2019 without open access. After publication in Volume 1, Issue 2, page 85-100, the author(s) decided to opt for Open Choice and to make the article an open access publication. Therefore, the copyright of the article has been changed to $\odot$ The Author(s) 2020 and the article is forthwith distributed under the terms of the Creative Commons Attribution 4.0 International License (http://creativecommons.org/licenses/by/4.0/), which permits use, duplication, adaptation, distribution and reproduction in any medium or format, as long as you give appropriate credit to the original author(s) and the source, provide a link to the Creative Commons license, and indicate if changes were made.

The original article has been corrected and can be found at https://doi.org/10.1007/s42757-019-0009-y.

$\square$ hibiki@purdue.edu 